\title{
El arduo proceso de reinserción laboral de los retornados en la periferia globalizada
}

\section{The intricate process of labor reinsertion of returning migrants in the globalized periphery}

\author{
Miguel Ángel Corona-JimÉnez*
}

\begin{abstract}
This paper presents reinsertion labor conditions of returning migrants in the "prosper" municipality of Cuautlancingo, Puebla, where the multinational automobile industry is located and connected with the global economy. The methodological approach is based on a survey, a typology, an integral concept of labor reinsertion, and the analysis of the use of remittances and savings of the returning migrants. The results confirm that the labor reinsertion process has been difficult and different to men and women. Moreover, this process has not been the same if the migrants returned willingly or unwillingly, or without achieving their goals, particularly in the context of a globalized periphery.
\end{abstract}

Keywords: returning migration, remittances and savings, labor reinsertion, gender, local development.

\section{Resumen}

Este trabajo muestra las condiciones de reinserción laboral de migrantes de retorno en el "próspero" municipio de Cuautlancingo, Puebla, lugar de enclaves trasnacionales automotrices conectados con la globalización. La estrategia metodológica comprendió una encuesta, una tipología, un concepto integrador de reinserción laboral y el análisis del uso de las remesas y de los ahorros de los retornados. Los resultados refieren que dicho proceso ha sido difícil, no igual para mujeres y hombres, y un tanto diferente para quienes regresaron de manera definitiva voluntaria, que para los que regresaron bajo condiciones forzadas o voluntariamente pero sin metas cumplidas, en un contexto de periferia globalizada.

Palabras clave: migración de retorno, remesas y ahorros, reinserción laboral, género, desarrollo local. 


\section{Introducción}

Para 2015 había más de 243.7 millones de personas en el mundo que vivían fuera de su lugar de origen (ONU, 2015). Sin embargo, la migración tiene características específicas dependiendo de los lugares y de su evolución histórica, en el caso de la migración de mexicanos hacia Estados Unidos (EE.UU.), los factores económicos han sido los más importantes y luego el desarrollo de las redes sociales (Durand y Massey, 2003). Esto es, las condiciones de desigualdad y de atraso del país han obligado a una gran cantidad de mexicanos a buscar oportunidades de progreso en el país del norte; movilidad que ha sido favorecida por los contactos y relaciones que tienen con parientes y amigos en algún lugar de EE.UU. Para ese mismo ańo, la población de origen mexicano (con segunda y tercera generación) rebasaba los 36.9 millones, de los cuales poco más de 5.8 millones se encontraba en calidad de no autorizados para trabajar y para permanecer en aquel país (PEW, 2016).

En México, las crisis económicas, el desempleo, la inflación y las devaluaciones en los últimos 35 años han incrementado la pobreza, la desigualdad, el rezago social y la pérdida de poder de compra de los salarios, con lo cual se han fraguado las causas y catalizadores de la gran migración hacia EE.UU. Este éxodo de mexicanos se ha extendido a todas las entidades del país, incluido el estado de Puebla, donde las emigraciones eran notorias en casi los 217 municipios para el 2010 y han continuado. Lo relevante es que las inmigraciones han aumentado (Corona-Jiménez et al., 2014), siendo principalmente retornados de los EE.UU.

En efecto, existe un proceso normal de retorno relacionado con el ciclo de la vida laboral del migrante (Pascual de Sans, 1983), pero se le ha sumado el retorno por causas relacionadas con cambios importantes en los lugares de destino, como las leyes antimigrantes y la crisis económica en EE.UU. que estalló en el 2008 (Canales, 2012) cuyos efectos más severos en la economía y en los mercados laborales se prolongaron hasta el 2013; posteriormente comenzó a disminuir el retorno y aumentar nuevamente la migración hacia EE.UU. (BBVA-Conapo, 2015), pero en condiciones cada vez más peligrosas y costosas. Es de mencionar que las cifras de retornados pueden estar subestimadas, ya que durante la administración del presidente Obama y hasta 2014 se habían deportado a más de 2.4 millones de personas, la gran mayoría mexicanos (PEW, 2014).

En el caso de Puebla, como se mencionó, la inmigración también se extendió a casi todos los municipios del estado y en proporción mayor a la emigración, es decir, entraron más de los que salieron para el 2010. De igual manera, la proporción de hogares con migrantes de retorno aumentó 
más de tres veces, de 0.66 a 2.08 entre los quinquenios 1995-2000 y 2005-2010 (Inegi, 2010).

En Cuautlancingo, municipio localizado en la zona metropolitana de la ciudad de Puebla y en donde se ubica la planta armadora de autos alemana, la cantidad de inmigrantes ascendió a 447 en 2010, pero esta cifra es muy conservadora, primero, porque muchos retornados no son visibles y han sido deportados, y segundo, porque la proporción de hogares con migrantes de retorno aumentó 4.7 veces entre 2000 y 2010, de 0.39 a 1.86 (Inegi, 2010). Esto representa un gran número de personas con necesidades apremiantes de reinserción social y laboral, en un municipio que ha tenido un acelerado crecimiento urbano-industrial en los últimos veinte años (Inegi, 2014), con una estructura económica que cada vez se aleja más de actividades del campo, que se ha orientado a la manufactura con medianas y grandes empresas principalmente, pero en donde el sector terciario alberga a la mayoría de la población ocupada en servicios de baja productividad como el comercio, la preparación de alimentos y servicios personales, entre otros.

En este trabajo se investiga el difícil proceso de reinserción laboral de migrantes de retorno en Cuautlancingo, Puebla, como parte de una reintegración social y económica más amplia, que les permita construir o reconstruir una base para poder vivir con dignidad y en armonía con su comunidad. Es importante mencionar que estudios desde esta perspectiva profundizan en lo complejo que se ha vuelto el fenómeno de la migración en México, y son sugeridos desde la óptica de Gandini et al. (2015).

Con los resultados de esta investigación se tiene una mejor aproximación a la problemática que enfrentan los migrantes de retorno en lugares más urbanos que rurales, más industriales y de servicios que agrícolas, con mayor presencia de actividades ligadas a los flujos de la globalización que al mercado local, todo con la intención de precisar recomendaciones para el diseño de políticas públicas de desarrollo, que ayuden a los migrantes en retorno a su reinserción laboral.

\section{Cuautlancingo, municipio de la periferia globalizada}

Cuautlancingo es un municipio localizado al noroeste de la ciudad de Puebla, tiene una superficie relativamente pequeña de $38.17 \mathrm{Km}^{2}$; para 2010 la población era de 79,153 personas, que representaba 1.37\% de la del Estado, pero lo que más debe llamar la atención es que la densidad de población aumentó de 1450 habitantes por $\mathrm{Km}^{2}$ en 2005, a 2074 en 2010 (Inafed, 2016), un aumento del 43\% en cinco ańos, cuyas manifestaciones fehacientes han sido el desplazamiento de la actividad agrícola 
y otras rurales, que han ido perdiendo importancia ante un acelerado proceso de urbanización, que se ha acompañado de una expansión comercial e industrial provocada en gran medida por el desarrollo de la industria automotriz, que ha atraído no sólo inversiones sino población de otros lugares fuera del municipio y del estado. Como ya se mencionó, en este municipio se encuentran grandes inversiones extranjeras como la planta Volkswagen con su parque industrial Finsa, que además concentra gran parte de la producción de autopartes, cuyo destino ha sido principalmente la exportación.

La población económicamente activa (PEA) de Cuautlancingo en 2010 estaba compuesta por 32,225 personas, $65 \%$ hombres y $35 \%$ mujeres, la tasa de desocupación era del 3.5\%, menor a la media del estado que era de 3.7\%, pero afectaba más a los hombres (75\%) (Inegi, 2010). Ahora bien, aunque su índice de marginación en 2010 era muy bajo, 35\% de la PEA tenía un ingreso menor a dos salarios mínimos y 36\% algún grado de hacinamiento (SFA, 2016), indicadores que denotan baja capacidad de compra y condiciones de vivienda muy limitadas, circunstancias propicias para la migración.

Es importante mencionar que por su localización y concentración de actividad económica, Cuautlancingo ha recibido inversiones en infraestructura urbana y de comunicaciones, que lo han conurbado más a la ciudad de Puebla con los beneficios que eso representa, por ejemplo, acceso a los mercados laborales urbanos y la derrama económica que conlleva.

No obstante que ha continuado la migración en Cuautlancingo, han retornado más, 447 para 2010, 65\% hombres y 35\% mujeres, la misma proporción que la PEA (Inegi, 2010). Pero en los últimos cinco años el número de retornados ha crecido aún más, según se menciona en las encuestas. Se trata de personas diferentes en ciertos aspectos a las que se fueron, cuyo principal reto es su reintegración familiar, comunitaria y económica, siendo ésta última quizá la más compleja y complicada porque se refiere precisamente a las condiciones laborales causales de la migración.

\section{El estado del arte y programas de reinserción laboral exitosa}

Ahora bien, cómo se ha visto el retorno. Los estudios sobre migración de retorno y procesos de reintegración comenzaron en Europa en los años sesentas, pero es hasta los setentas que comienzan a aparecer las problemáticas de reinserción a que se enfrentan los migrantes en el retorno y mejores tipologías para estudiarlos. A partir de los noventas comienzan los estudios en los países del sur del planeta, con sus respectivos contextos 
y problemáticas, destacando los relacionados con el comportamiento económico del retornado, el emprendimiento, la perspectiva de género y los obstáculos a la reinserción, concluyendo que la reintegración económica del retornado es escabrosa. Después del 2000 los trabajos se orientaron más a las condiciones de reinserción, emergiendo el papel del migrante como agente de desarrollo por su capital financiero y humano, esto en la perspectiva de agencias internacionales como el Banco Mundial; en el mismo tenor el uso del ahorro como catalizador de la reintegración, concluyendo que la experiencia migratoria de trabajo era el detonante del emprendimiento, todo esto es reseñado por Fernández-Guzmán (2011). Estudios más recientes enfatizan el papel del migrante retornado como trasmisor de conocimiento e innovación en procesos de industrialización en sus países de origen (Klagge y Klein-Hitpab, 2010; Murphy, 2000 y Montoya et al., 2011), como emprendedor en sus procesos de reintegración mediante el uso de las remesas (Batista et al., 2014), y como alternativa de empleo (Zelekha, 2013), de igual manera se ha enfatizado sobre la utilidad de la experiencia migratoria en la reintegración laboral (Reinhold y Thom, 2013; Wang, 2015).

En esa perspectiva, después de la crisis mundial del 2008, que puso en jaque los mercados laborales, el tema del retorno entró en las agendas de varios gobiernos europeos y de organizaciones de cooperación internacional debido al grave problema del desempleo. La intención era unificar esfuerzos para construir marcos institucionales que facilitaran el retorno voluntario y la reintegración de migrantes a sus lugares de origen. Para ello establecieron acuerdos bilaterales con los países de origen, para planear los retornos y crear condiciones favorables de adaptación, con la intención de que fueran duraderos o permanentes. Esto significó un grado de reconocimiento, corresponsabilidad y avance en la conceptualización del proceso migratorio, sobre todo entre países europeos y sudamericanos, estos fueron los casos de España, Reino Unido e Italia, con sus contrapartes Bolivia, Colombia y Ecuador, donde programas de retorno asistido y de retorno voluntario alentaron la decisión de las familias para regresar a sus países de origen, desarrollando algún negocio o actividad productiva, capitalizando los aprendizajes de la experiencia migratoria.

Estos programas fueron financiados por los ministerios del Empleo y por el Fondo Europeo de Retorno (OIM, 2006; EMN, 2009; ACCEM, 2009; Acobe, 2010). Otro proyecto fue el de Ventanillas Únicas para la reinserción sostenible de retornados vulnerables latinoamericanos, entre 2012 y 2013, que integraba apoyo psicológico, social, sanitario, formativo y laboral, que se extendía además de los países mencionados a Brasil, Chile, Perú, Paraguay y Uruguay, con buenos resultados en cuanto a creación de negocios y duración del retorno. Existen otros proyectos com- 
plementarios gestionados y subvencionados por las ONG, pero en todos los casos se realizan con protocolos trasnacionales e integrales para garantizar su efectividad (Parella y Petroff, 2014).

Lamentablemente esto no ha sido así en el caso de la migración MéxicoEstados Unidos, por el contrario desde la administración del presidente Obama y seguida por la del presidente Trump, la deportación y el asedio han sido las pautas en su trato hacia los migrantes. Por lo tanto, el retornado que llega a México de manera voluntaria o forzada tiene que enfrentar un proceso no fácil de reintegración familiar, social, cultural y económica, que en varios casos puede ser facilitado por el uso patrimonial o productivo de las remesas enviadas previamente o por un retorno con ahorros suficientes, pero que en la mayoría de los casos no es así (Corona-Jiménez y ÁvilaGuerra, 2017). En este trabajo se analiza el arduo proceso de reinserción laboral de los retornados en la periferia globalizada.

\section{La migración de retorno y la reinserción económica en perspectiva}

La gran mayoría de los migrantes se van en búsqueda de recursos económicos que no consiguen en el lugar de origen, para llevar una vida en familia con mínimos de subsistencia que les permitan formar un patrimonio y otras oportunidades de progreso. Ciertamente, la escasez de empleos bien remunerados en sus comunidades o dentro del mismo país, más la red de relaciones que tiene, prácticamente lo han llevado a él o al grupo familiar a decidir emigrar a un lugar que también lo atrae. El migrante trabajando en EE.UU. generalmente envía remesas a la familia, y dependiendo de la actividad en la que se emplee, las capacidades, habilidades y actitudes que logre adquirir, del tiempo que dure su estancia, (Cobo, 2008), del ahorro que alcance a acumular y del uso de esas remesas principalmente, podrá ir preparando su regreso (Cassarino, 2004).

$\mathrm{Al}$ retornar, lo primero que afronta es una realidad un tanto distinta a la que dejó, no sólo en el ámbito familiar, sino sobre todo en el económico. La necesidad de generar ingresos lo llevará inmediatamente a buscar una reinserción laboral, que le permita cubrir sus principales gastos de subsistencia y de ser posible generar ahorro para continuar formando patrimonio. Por lo tanto, lo que demandará serán oportunidades de empleo o de iniciar un trabajo por cuenta propia. Mientras lo logra o para lograrlo, habrá utilizado los activos comprados con las remesas que envió durante su experiencia migratoria o el ahorro con el que haya regresado, si es que pudo acumular. Esto último representa un colchón financiero que le dará cierto margen para esperar y facilitar su reinserción 
laboral. Sin embargo, no todos los retornados tienen o trajeron recursos suficientes, pero sí en todos los casos se requiere de condiciones propicias para que se empleen, se auto-empleen o se vuelvan empleadores (Massey y Espinosa, 1997).

También el que se fue es un tanto distinto al que retorna, la mayoría regresa con aprendizajes de la cultura del lugar de destino (respeto a la ley o al ahorro, principalmente), con conocimientos, habilidades, actitudes y expectativas animadas por la sociedad en que convivió, algunos con recursos económicos y entusiasmo para progresar en su comunidad (Corona-Jiménez, 2008), con capital humano, social y monetario, como se dice académicamente. En esta perspectiva, los migrantes en retorno no son los mismos que se fueron, y sin embargo, regresan a sus comunidades y al país donde las condiciones económicas y sociales no han mejorado lo suficiente y en muchos lugares han empeorado.

Cabe preguntar por lo tanto, ¿cuál es el principal reto de los migrantes de retorno? su reincorporación al entorno económico, que implica principalmente su reinserción laboral y utilizar lo adquirido en su experiencia migratoria para una mejor reinserción social en general. Pero ¿̇erá lo mismo para las mujeres que para los hombres? ¿será lo mismo para los que regresaron voluntariamente después de haber cumplido sus metas, que para los que regresaron de manera forzada por deportación, que para los que regresaron de manera voluntaria pero con frustración por no haber cumplido sus metas? Y haciendo un doble sentido en el proceso de reintegración (Gandini, et al., 2015: 105) ¿¿dependerá sólo de sus condiciones personales o también de las del entorno económico y social?

Sin duda el ser migrante en retorno es una condición pero no representa homogeneidad en el grupo, ya que no todos regresaron por los mismos motivos y en las mismas circunstancias.

Tipos de retornados. Esto ha dado pauta para algunos planteamientos sobre los tipos de migrantes desde hace algunos años: los primeros animados por un retorno natural de acuerdo con una de las clásicas leyes de Ravenstein (Castillo, 1997: 33), otros considerando migraciones conservadoras e innovadoras que retornan, esto es, unos regresan después de haber logrado sus objetivos tanto en el lugar de destino como en el de origen, e innovan e influyen en su comunidad, y otros que por inadaptación regresan frustrados (Cerase, 1974). El planteamiento más cercano a la realidad de los retornados en México ha sido el de Jorge Durand (2004 y 2006), que ha profundizado sobre la tipología de los retornados, incluso señalando diferencias de género.

Por ejemplo, en el caso de las mujeres, hay menor proclividad al retorno porque la facilidad laboral y la generación de ingreso no son iguales en México, y un obstáculo adicional se presenta en el retorno, al perder 
libertades ganadas cuando el cónyuge pretende que regrese a sus roles anteriores de ama de casa sumisa (Durand, 2004: 108). Con respecto a los motivos y circunstancias del retorno, el mismo autor propone una clasificación con cinco categorías: Definitivo voluntario, Temporal, Transgeneracional, Forzado y Voluntario fracasado, para explicar con más detalle la composición del grupo de retornados (Durand, 2004: 104).

\section{Estrategia metodológica}

Para la realización de esta investigación se levantó una encuesta a 72 migrantes en retorno en el municipio de Cuautlancingo, Puebla, desde abril de 2015 hasta septiembre de 2016. Esta muestra por conveniencia se formó a partir de recomendación personal, a semejanza de una bola de nieve, para poder alcanzar un número aceptable de encuestas aplicadas, dada la poca visibilidad social de los retornados. Es importante resaltar que hasta donde lo permitió la información se contempló su análisis por género.

De acuerdo con las evidencias recolectadas a través de las encuestas aplicadas para este trabajo (McKinney, 1962), se clasificaron a los retornados en tres categorías parecidas a las que propone Durand (2004): Definitivo voluntario, cuya principal característica es que regresa después de haber cumplido sus metas u objetivos; Forzado, es el retornado por deportación o con problemas con la ley, principalmente; y el Voluntario fracasado, que regresa por haber perdido su empleo, porque él o algún familiar en el lugar de origen padecieron una enfermedad o por no adaptarse a su entorno de destino. Cabe aclarar dos cosas: que fue difícil su clasificación porque la mayoría respondió motivos familiares para su regreso, por ello se recurrió a otras respuestas complementarias, y segundo, más difícil, fue localizar migrantes retornados en las comunidades, debido a que no siempre son visibles por diversos motivos como: la vergüenza de haber sido deportado, de haber regresado sin o con pocos recursos, para evitar que se les acerquen para pedirles dinero, o por cuestiones de inseguridad, entre los principales.

Para realizar el análisis de la reintegración laboral se consideró el uso de los recursos económicos previos (remesas) y al retorno, desde una tipología de los retornados, también se realizó un análisis inter-temporal sobre la movilidad ocupacional en EE.UU. y al retornar, como complemento se utilizó un concepto integrador para analizar y evaluar la reinserción laboral como un constructo formado por cuatro elementos: la actividad que desempeñó y desempeña, y tres movilidades, la ocupacional, en el ingreso y en la posición en el trabajo. Para concluir, se analizan las 
percepciones de los retornados en lo referente a las condiciones que favorecen u obstaculizan la reinserción, y sus expectativas como medio para evaluar en parte la satisfacción en sus procesos de reinserción laboral. La información se capturó y procesó en el programa estadístico SPSS y se complementó con cálculos en hojas de Excel.

Con todos los elementos anotados, enseguida se presenta el análisis socioeconómico de los retornados del municipio de Cuautlancingo, Puebla.

\section{Perfil socioeconómico de los retornados a Cuautlancingo}

La muestra de migrantes en retorno del municipio de Cuautlancingo estuvo formada por 57 hombres $(\mathrm{H})$ y 15 mujeres $(\mathrm{M})$, representando los primeros $79 \%$ de la muestra y, las segundas, $21 \%$. Para hacer más comprensible los resultados se utilizarán proporciones porcentuales. Por lo que respecta al estado civil, la mayoría estaba casado o unido, $67 \%$ de las $\mathrm{M}, \mathrm{y} 79 \%$ de los $\mathrm{H}$. En su posición dentro de la familia $98 \%$ de los $\mathrm{H}$ y $40 \%$ de las $\mathrm{M}$ eran jefes de familia.

El nivel de escolaridad más frecuente tanto en $\mathrm{H}$ como en $\mathrm{M}$ fue el de secundaria, seguía el de preparatoria donde la proporción de las M era mayor, que contrastaba con el de nivel primaria donde los hombres eran mayoría. Sin embargo, es importante señalar, que aunque con participaciones menores al 9\%, había $\mathrm{M}$ y $\mathrm{H}$ con estudios universitarios.

Los ingresos de los hogares de los migrantes en retorno provenían principalmente por un empleo o trabajo en la comunidad (64\%), por negocio propio $(18 \%)$ o por un empleo en una ciudad cercana (10\%). En dinero, $41 \%$ de los hogares tenían un ingreso mensual de entre uno y tres salarios mínimos (SM), 30\% entre más de tres y hasta cinco SM, 10\% entre más de cinco y hasta siete SM, y otro 10\% más de siete SM. Esto es, el ingreso de la mayoría de los hogares de migrantes retornados se encontraba muy alejados de poder ahorrar y formar o seguir formando un patrimonio familiar en México.

\section{La experiencia migratoria laboral}

De acuerdo con la encuesta, la edad promedio en que migraron $\mathrm{H}$ y $\mathrm{M}$ fue de 30 años. La duración de la experiencia migratoria fue de 5.6 años en $\mathrm{H}$ y 3.1 ańos en $\mathrm{M}$, tiempos relativamente suficientes en muchos casos, para haber adquirido capacitación laboral, cierto grado de aculturamiento de la sociedad de destino y recursos económicos. Los principales motivos 
por los que migraron fueron económicos, para comprar bienes $(33 \%)$, para tener empleo y un ingreso (15\%), y para pagar deudas (14\%).

Los principales lugares de destino fueron en primer lugar Nueva York, en segundo California y en tercero Illinois, en estos tres estados se concentraban 78\% de los encuestados. Para pasar a EE.UU., 75\% lo hizo con dinero prestado que después pagaría e igualmente consiguieron trabajo inmediatamente con la ayuda de un familiar o amigo.

La gran mayoría de los migrantes pasaron de manera clandestina, financiados por un familiar y lograron un empleo gracias a su red social en los EE.UU., laboraban principalmente en restaurantes, comercios, en actividades de cuidado personal, cuidando niños y otros servicios; otra parte se empleó en la construcción, principalmente hombres, y pocos en actividades agrícolas. El tipo de trabajo en general era manual y con ciertos niveles de calificación. La mayoría ganaba un salario semanal de entre 200 y 400 dólares, siendo proporcionalmente más las M, en el rango de 401 a 600 dólares y de 601 a 800 dólares, las proporciones mayores eran de H. En estos tres grupos se ubicaban $88 \%$ de los encuestados. Con esos niveles de ingreso, aunque bajos para esa economía, la gran mayoría de los $\mathrm{H}$ y M podían ahorrar, e incluso la tercera parte de ellos tenían una cuenta bancaria. En cuanto a sus condiciones laborales, sólo una mínima parte de las $\mathrm{M}$ y de los hombres tenían alguna prestación como ayuda por enfermedad.

Durante su experiencia laboral casi la mitad de las $\mathrm{M}$ y de los $\mathrm{H}$ adquirieron habilidades y actitudes para aumentar su productividad, por ejemplo ocho de cada $10 \mathrm{H}$ y tres de cada $10 \mathrm{M}$ aprendieron inglés para comunicarse, lo cual les dio mayor movilidad en el mercado laboral y la oportunidad de aumentar sus ingresos. Otros más aprendieron el manejo de maquinaria, pero quizá lo más importante fue el acceso que tuvieron a la tecnología, sobre todo de la información. Finalmente, ocho de cada $10 \mathrm{H}$ y $\mathrm{M}$ enviaban remesas a México.

\section{El uso de los recursos económicos de la migración y del retorno}

Un factor importante en la vivencia del retorno es el motivo principal por el que el migrante regresó (Durand, 2004), ya que va a influir en la manera cómo se reintegra a su entorno, específicamente, el económico. En este sentido, los motivos principales declarados por los retornados estuvieron relacionados en $46 \%$ de los casos con motivos familiares, en $22 \%$ con procesos de deportación, en $7 \%$ con motivos de salud y en $4 \%$ con desempleo. Es importante señalar que en el caso de la deportación, ésta afectó más a los $\mathrm{H}$ y la enfermedad a las $\mathrm{M}$. 
Sin embargo, con base en la clasificación utilizada en este trabajo, se identificaron tres tipos de migrantes: el que regresó definitivamente de manera voluntaria, que en la muestra representaron $28 \%$; el que regresó bajo condiciones forzadas que representaron 36\%; y el que regresó de manera voluntaria pero en condiciones de fracaso, que representó el otro $36 \%$ (gráfica 1).

\section{Grafica 1 \\ Tipología del retorno}

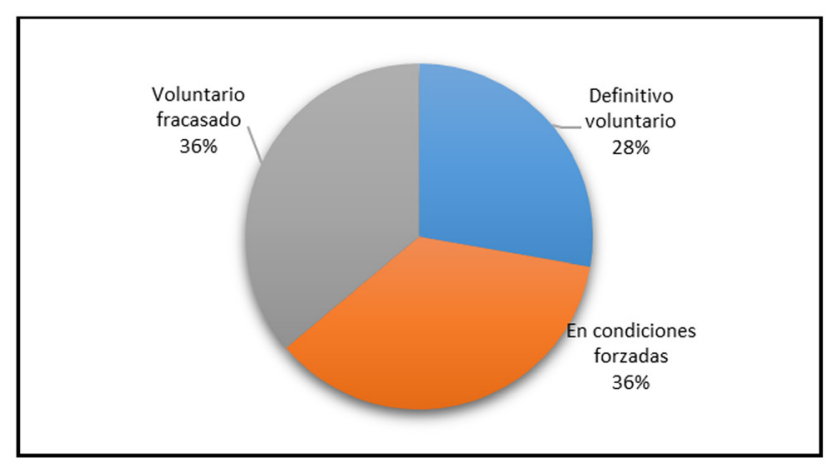

Fuente: elaborado con resultados de encuesta aplicada a migrantes de retorno en el municipio de Cuautlancingo, Puebla, 2015-2016 (Ibero/Puebla-BUAP, 2016).

Con base en esta tipología, se analiza a continuación el uso de los recursos de la migración, las remesas y el ahorro del migrante en retorno.

\subsection{Uso de las remesas por tipo de migrante retornado}

Se considera el uso de las remesas en el estudio de la migración de retorno, porque fueron recursos que envió el migrante para la sobrevivencia de sus familiares, y para la formación de un patrimonio, el cual le ayudaría a su regreso.

Sobre el uso de las remesas, los estudios que se han realizado han coincidido en que más del $80 \%$ las familias lo destinaban al consumo (Corona-Vázquez, 2000), lo que se ha identificado en este trabajo como bienes de sustento, pero si el migrante consigue un empleo con un ingreso mayor o prolonga su estancia, la cantidad de remesas aumentará y la familia tenderá a gastar menos en consumo y a invertir más en bienes patrimoniales (ampliación, construcción, compra de casa y terrenos), bienes productivos (emprendimiento, consolidación del negocio, en salud y educación, principalmente (Corona-Jiménez, 2014). Todo lo cual es muy normal porque la remesa es parte de un salario que así lo utilizaría 
cualquier familia, la única diferencia es que se trata de un salario ganado en EE.UU. que se gasta internacionalmente.

En general, los $\mathrm{H}$ usaban las remesas de la siguiente forma, para consumo (30\%), vivienda (19\%) y educación de los hijos (8\%). En las M, su uso principal era también el consumo (40\%), luego la educación (29\%) y después la vivienda (14\%), estos porcentajes son consistentes con la duración promedio de la experiencia migratoria que no es tan corta relativamente. También es conveniente señalar que el uso de las remesas y, en general de los recursos económicos, sigue la lógica de satisfacer las necesidades básicas primero y después las secundarias o superfluas.

Ahora bien, si suponemos que los migrantes que han regresado voluntariamente han cumplido con sus metas, a diferencia de los que han sido forzados a regresar o los que han regresado voluntariamente pero frustrados y por lo tanto con metas no alcanzadas, es de esperarse que los usos de los recursos derivados de la migración, como son las remesas usadas por las familias en el lugar de origen, y los ahorros de los retornados presenten diferencias, debido a lo voluntario, o no, del retorno (gráfica 2).

\section{Gráfica 2}

\section{Uso de las remesas según tipo de retorno}

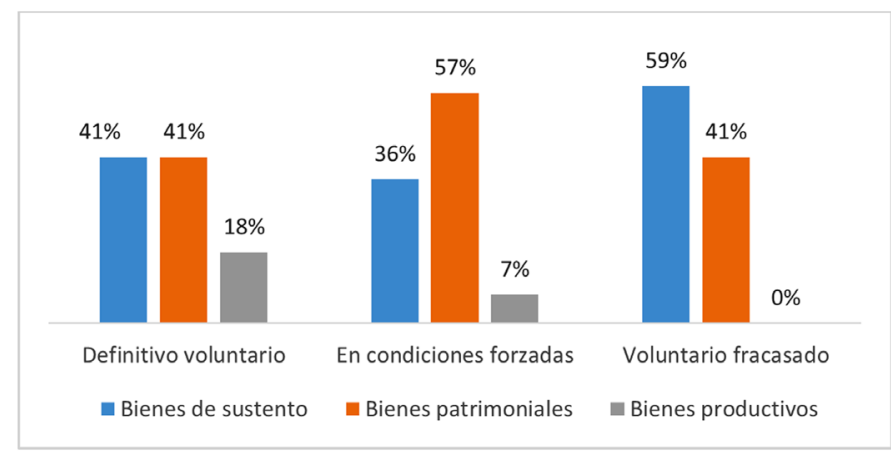

Fuente: elaborado con resultados de encuesta aplicada a migrantes de retorno en el municipio de Cuautlancingo, Puebla, 2015-2016 (Ibero/Puebla-BUAP, 2016).

En el caso de los retornados clasificados como definitivos voluntarios, sus remesas las habían usado sus familias en $41 \%$ de los casos para comprar bienes de sustento para la manutención, pero también en esa misma proporción (41\%) para adquirir bienes patrimoniales, como la construcción o ampliación de la casa y la compra de terreno, el restante $18 \%$ lo habían invertido en bienes productivos, es decir, para generar ingresos, en esto caben tierras para sembradíos, maquinaria e infraestructura agrícola, animales, establecimiento de un negocio comercial o de una empresa de 
producción. En estos retornados el tiempo de su experiencia migratoria fue suficiente para alcanzar sus metas, según lo declararon en la encuesta.

Por su parte en los deportados, las familias habían gastado en bienes de sustento $36 \%$ de las remesas, $57 \%$ en bienes patrimoniales y $7 \%$ en bienes productivos. En esta distribución se aprecia que para el grupo encuestado y tipificado, su proceso de formación de patrimonio se encontraba en pleno y que incluso se comenzaba a observar en algunos de ellos la inversión en bienes productivos generadores de ingreso. En este grupo se encontraban migrantes retornados con más de un ańo de estancia en EE.UU. y con un proceso de formación de patrimonio suspendido súbitamente.

En los retornados voluntarios pero con signos de fracaso, sus familias habían utilizado 59\% de las remesas en la compra de bienes de consumo y el restante $41 \%$ en bienes patrimoniales. En este grupo se encontraba una buena parte de los de menor tiempo en la experiencia migratoria, con más necesidades familiares apremiantes de subsistencia, pero considerando que la migración era una alternativa para formar patrimonio como mejorar la casa, su ampliación y, en pocos casos, iniciar su construcción. Como estos procesos se vieron interrumpidos, podrían ser sujetos de una atención especial al igual que los deportados.

\subsection{Uso de los ahorros por tipo de migrante retornado}

El otro recurso de la migración, muy importante sobre todo para la reinserción laboral del migrante de retorno, es el ahorro con el que regresó, ya que esto le ayudará a buscar con menos presión un empleo, a desarrollar un trabajo por su cuenta o a continuar o emprender un negocio. Es importante aclarar que las cifras utilizadas fueron calculadas a un año base para ser comparables en el tiempo.

$\mathrm{Al}$ retorno, los ahorros pudieron ser utilizados en fines parecidos a los de las remesas, pero se esperaría que las proporciones fueran más hacia bienes patrimoniales, productivos y duraderos, y no tanto de sustento; sin embargo, las condiciones del retorno pueden influir para que sea diferente, así como el uso de las propias remesas que hayan realizado las familias.

Así, cuando retornaron, las mayores proporciones de ahorro fueron traídas por los hombres: $36 \%$ trajo en promedio $\$ 250,000 ; 17 \%$, $\$$ 75,000 ; otro $17 \%$, \$37,500; $10 \%$, $\$ 750,000$; otro $10 \%$, $\$ 15,500$; y $5 \%$ más de un millón de pesos. Por su parte, $40 \%$ de las mujeres trajo en promedio $\$ 15,500 ; 20 \%$, $\$ 75,000$; otro $20 \%$, $\$ 250,000$; y $10 \%$ más de un millón. Los restantes $10 \%$ de las mujeres y $5 \%$ de los hombres habían regresado con ahorros de hasta seis mil pesos. 
Considerando nuevamente la tipología de los migrantes de retorno se analizó el uso de los ahorros. En los tres grupos, las proporciones más altas correspondieron a la inversión en bienes patrimoniales, siendo aún más alta en los deportados; enseguida las proporciones de ahorro se usaron para comprar bienes duraderos como muebles, electrodomésticos y vehículos para uso familiar, siendo más alta en los retornados voluntarios fracasados; las siguientes proporciones se usaron en la inversión en bienes productivos, siendo la mayor en los retornados definitivos voluntarios y cero en los voluntarios fracasados; finalmente y, como era de esperarse, las proporciones más pequeñas de ahorros fueron en la compra de bienes de sustento, siendo nula en los retornados definitivos voluntarios (gráfica 3).

\section{Gráfica 3}

\section{Uso principal de los ahorros según tipo de retorno}

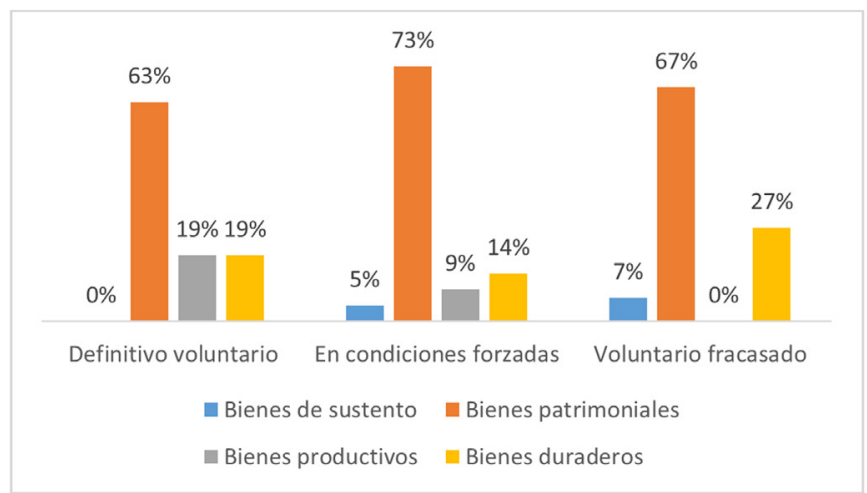

Fuente: elaborado con resultados de encuesta aplicada a migrantes de retorno en el municipio de Cuautlancingo, Puebla, 2015-2016 (Ibero/Puebla-BUAP, 2016).

La explicación que subyace es que en el caso de los definitivos voluntarios, al haber cumplido sus metas y entre ellas haber cubierto sus necesidades básicas, el ahorro se utilizaba para inversión en cualquiera de los tipos de bienes no básicos, por supuesto patrimoniales (63\%) pero también productivos en una proporción considerable (19\%), porque ya desde antes del retorno habían enviado remesas para esos fines e iniciado procesos de inversión productiva. El otro 19\% lo destinaron para equipar sus hogares y comprar vehículos.

En los deportados el uso de los ahorros seguía una distribución parecida a la anterior, la proporción más alta fue en bienes patrimoniales (73\%), seguía la de bienes duraderos (14\%), luego la de bienes productivos $(9 \%)$ y la más baja en bienes de sustento (5\%). Esto se explica porque se trata de migrantes sin alternativa de regreso a EE.UU., con 
procesos de formación de patrimonio interrumpidos, e incluso en algunos casos sin haber superado el umbral de consumo de sustento.

En los voluntarios deportados también la distribución tenía una variante. Si bien la proporción más alta de ahorros se había destinado a invertir en bienes patrimoniales (67\%), la que seguía en proporción considerable era la de bienes duraderos (27\%), seguida muy por debajo por la de bienes de sustento (5\%), es de destacar que en este grupo no hubo ahorros destinados a bienes considerados como productivos. La explicación tiene sentido al considerar que se trata en su mayoría de personas que salieron en busca de mayores ingresos para mejorar sus condiciones de vivienda y de consumo, con procesos de acumulación de patrimonio interrumpidos, con experiencias migratorias más cortas, por lo que pensar en desarrollar una actividad generadora de ingreso la veían más lejana. La mayoría con deseos de regresar a EE.UU.

En síntesis, los resultados de esta muestra precisan que la mayoría de los retornados pudieron invertir sus ahorros con fines patrimoniales y para equipar sus hogares, lo cual no sólo representó aumento del nivel de vida, sino potenciar su capacidad económica para enfrentar la reinserción laboral.

\section{La compleja reinserción laboral en el retorno, desde un concepto integrador}

Una vez retornado, el exmigrante enfrenta su primer desafío que es la reintegración a su familia y a la comunidad, pero el siguiente y, quizá determinante, es el de la reinserción laboral, que consiste en volver a realizar una actividad que le permita obtener un ingreso para sus gastos de sobrevivencia, por ello se considera en este trabajo que se trata de un concepto integrador que implica: el tipo de actividad que realiza y sus movilidades ocupacional, del ingreso y de la posición en el trabajo. Por tratarse del retorno su valoración considera la experiencia migratoria, y compara cada uno de los cuatro elementos laborales antes y después de migrar.

\subsection{Cambios sectoriales en la actividad laboral}

Uno de los análisis más importantes del retorno es el de la continuidad laboral en los sectores económicos, ya que esto permite observar trayectorias laborales desde la perspectiva económica y derivar consecuencias a nivel de la macroeconomía de los lugares. Antes de migrar, 29\% eran empleados; $21 \%$, obreros; $15 \%$, comerciantes; $8 \%$, albañiles, y otro $8 \%$ 
desempeñaban algún oficio; el resto eran estudiante, 7\%; amas de casa, $6 \%$; jornaleros, 3\%; y productores agrícolas, $1 \%$. En EE.UU. la mayor proporción, $58 \%$, eran empleados; $12 \%$, trabajadores de la construcción; $10 \%$ desempeńaban algún oficio; $7 \%$ eran obreros y $6 \%$ comerciantes; sólo 3\% seguía siendo jornalero y $1 \%$ productor agrícola. Al retornar, la mayor proporción era la de los comerciantes con 36\%, seguía la de empleados con $21 \%$, la de obreros con $14 \%$, los que desempeñaban un oficio representaban $8 \%, 7 \%$ eran albañiles, $4 \%$ amas de casa, $3 \%$ estudiantes y el resto con $1 \%$, eran jornaleros, productor agrícola, trabajadora doméstica y desempleado.

A partir de los resultados anteriores es posible realizar las siguientes afirmaciones, los migrantes de Cuautlancingo salen de una estructura de empleo sectorial terciarizada (con predominio del sector terciario), con notable trabajo manual y baja productividad; se emplean en EE.UU. y moldean una estructura ocupacional terciarizada, pronunciadamente orientada a los servicios, con un poco menos trabajo manual, con ciertos grados de calificación y de mayor productividad, los ingresos que perciben lo denotan; retornan a Cuautlancingo y encuentran cabida moldeando otra vez una estructura terciarizada, con fuerte inclinación hacia actividades con trabajo manual de cierta calificación, baja productividad y remuneración, como empleados de establecimientos y cuando no hay vacantes una buena parte incursiona en el comercio al menudeo por cuenta propia, generalmente en condiciones de informalidad, tal como se ha reportado a nivel nacional ( $\mathrm{Li}, 2015)$. Los resultados de esta movilidad sectorial sugieren que la mayoría de los retornados, aún con mejor calificación, no encuentren suficientes oportunidades, y los que iniciaron una actividad por cuenta propia no necesariamente fue por emprendimiento voluntario (Cassarino, 2004), sino por alternativa forzada, por ello pocos son los que progresan.

\subsection{Movilidad ocupacional durante y después, por tipo de migrante}

El segundo elemento del concepto integrador de reinserción laboral es la movilidad ocupacional, que se refiere a la capacidad para tener un trabajo u ocupación mejor al que se tenía antes de migrar en el lugar de origen, y ésta puede ser ascendente, descendente o sin movilidad (Cobo, 2008), Para entender mejor este proceso es importante mencionar que la movilidad ascendente se presenta al pasar de trabajo manual a no manual, y de trabajo no calificado a calificado. Por lo tanto también puede ser descendente, sin movilidad y no determinada cuando no es posible hacer la comparación. 
Para tener una mejor aproximación a la movilidad ocupacional, además de determinarla, se cruzó con los tipos de migración de retorno, y el ejercicio se realizó tanto para las ocupaciones desempeñadas en la experiencia migratoria como para las desempeńadas en el retorno. Esto permitió observar mejor como la economía del lugar es determinante para mejorar las condiciones de trabajo de las personas.

Durante su estancia en los EE.UU. los que tuvieron la mayor movilidad ascendente (40\%) fueron los definitivos voluntarios, en segundo lugar los voluntarios fracasados (31\%) y por último los deportados (15\%). Es importante resaltar que en lo que respecta a la movilidad descendente sólo la presentaron 19\% de los deportados y $8 \%$ de los voluntarios fracasados. Sin embargo, las mayores proporciones de los tres tipos de migrantes no presentaron movilidad, y en los no determinados, la mayor proporción fue la de los voluntarios fracasados. Lo anterior implica que quienes cumplieron con sus metas y retornaron, en una buena parte, lograron una movilidad ascendente por el tipo de actividad que desempeñaban con respecto a la que desempeñaban antes de migrar. Sin embargo, también casi un tercio de los retornados voluntarios fracasados ascendieron, pero no así, los deportados; por lo tanto, en este ejercicio de análisis el tipo de migrante no fue tan diferente entre los retornados voluntarios pero sí con los que retornaron en condiciones forzadas (gráfica 4).

En el retorno, la movilidad ocupacional presentó grandes contrastes: en principio, los que lograron una movilidad ascendente fueron pocos y se distribuyeron por tipo de migrante de la siguiente manera; $27 \%$ fueron deportados, $15 \%$ definitivo voluntario y sólo $4 \%$ correspondió

\section{Gráfica 4}

Movilidad ocupacional en Estados Unidos de América

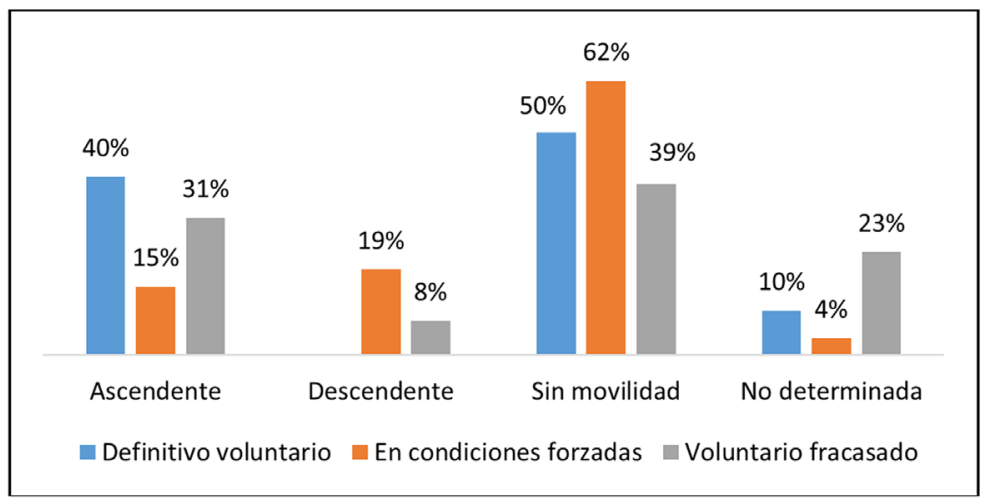

Fuente: elaborado con resultados de encuesta aplicada a migrantes de retorno en el municipio de Cuautlancingo, Puebla, 2015-2016 (Ibero/Puebla-BUAP, 2016). 
a los voluntarios fracasados. En la movilidad descendente, la mayor proporción (39\%) fue la de voluntario fracasado. En la clasificación -sin movilidad- estuvieron nuevamente las mayores proporciones entre $50 \%$ y $65 \%$, y en la -no determinada- la menor proporción fue la de deportado, $4 \%$ (gráfica 5).

\section{Gráfica 5 \\ Movilidad ocupacional en México}

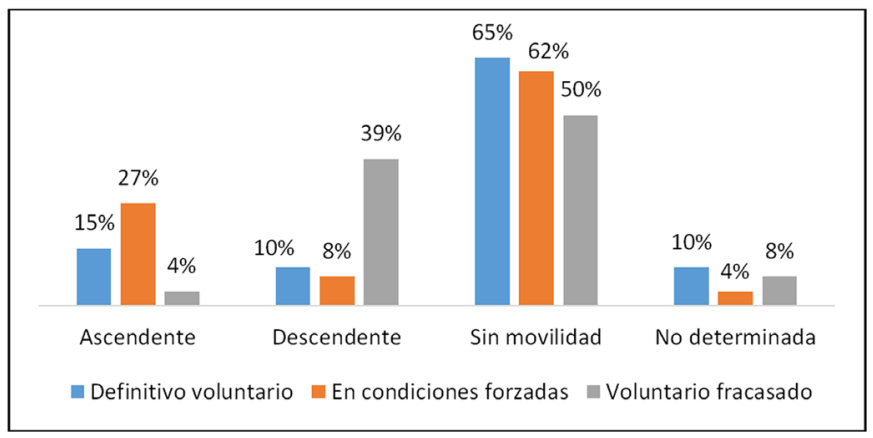

Fuente: elaborado con resultados de encuesta aplicada a migrantes de retorno en el municipio de Cuautlancingo, Puebla, 2015-2016 (Ibero/Puebla-BUAP, 2016).

Los resultados sugieren que el tipo de migrante tiene cierta vinculación con la movilidad ocupacional ascendente, aunque habría que estudiarla más a fondo para entender por qué en este caso, los deportados fueron los que alcanzaron la mayor participación, y por qué los voluntarios fracasados representaron una gran parte de los que se clasificaron con movilidad ocupacional descendente.

Las grandes proporciones de los sin movilidad prueban que la mayoría de las personas regresaron a realizar actividades parecidas, si no es que iguales a las que tenían antes de migrar. Considerando los resultados de los dos ejercicios de movilidad tanto en EE.UU. como en México, se puede concluir que para la muestra de migrantes de retorno de Cuautlancingo, los migrantes lograron mayor movilidad ascendente en los mercados de trabajo del país del norte, que en los mercados de trabajo de su lugar de retorno. Por lo tanto, lo que sí influye y es determinante son las oportunidades que ofrece la economía del lugar y en especial los mercados de trabajo, por lo que las políticas de desarrollo son fundamentales. 


\subsection{Ingreso antes y después de migrar}

El tercer elemento de la reinserción laboral como concepto integrador es la movilidad del ingreso antes y después de migrar, aunque el resultado es en general, está basado en las respuestas de cada uno de los encuestados. En él se aprecia una mejoría en los ingresos de la mayoría de los retornados con respecto al ingreso que tenían antes de migrar; sin embargo, se aprecia mayor en las $\mathrm{M}$ que en los $\mathrm{H}$. Mientras en el rango de cero a un Salario Mínimo (SM) los $\mathrm{H}$ bajaron de 33\% a 13\%, las M bajaron de $47 \%$ a $12 \%$. En el rango de más uno a tres SM los $\mathrm{H}$ subieron de $44 \%$ a $47 \%$, en tanto que las M saltaron de $20 \%$ a $44 \%$. Algo similar sucedió en el rango de más tres a cinco SM, los hombres aumentaron de $11 \%$ a $20 \%$, en tanto que las mujeres volvieron a saltar de cero a $25 \%$. Para el rango de más cinco a siete $\mathrm{SM}$ los $\mathrm{H}$ desaparecen en tanto que las $\mathrm{M}$ pasaron de $7 \%$ a $11 \%$. Igual para el rango de más de siete a $10 \mathrm{SM}$, los $\mathrm{H}$ desaparecen pero las $\mathrm{M}$ aparecen con el $2 \%$. Para el último rango de más de $10 \mathrm{SM}$, los $\mathrm{H}$ no aparecen pero las mujeres descienden de $7 \%$ a 4\% (gráfica 6).

\section{Gráfica 6}

\section{Ingreso antes y después de migrar}

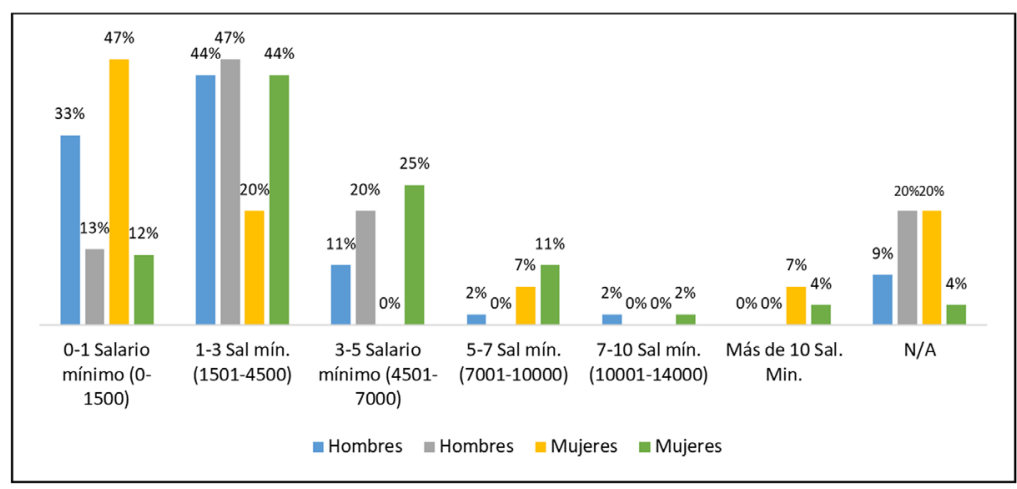

Fuente: elaborado con resultados de encuesta aplicada a migrantes de retorno en el municipio de Cuautlancingo, Puebla, 2015-2016 (Ibero/Puebla-BUAP, 2016).

Es importante señalar que no fue posible identificar el ingreso en $20 \%$ de los $\mathrm{H}$ y en $4 \%$ de las $\mathrm{M}$; sin embargo, el análisis es meritorio porque las respuestas sobre ingresos son las más difíciles de recolectar en las encuestas por las condiciones de inseguridad que se viven.

De los resultados anteriores se pueden hacer las siguientes aseveraciones: a) que los $\mathrm{H}$ tenían ingresos superiores a los de las mujeres antes de 
migrar; $b$ ) que en $20 \%$ de $\mathrm{H}$ y $32 \%$ de $\mathrm{M}$ sus ingresos aumentaron en el retorno con respecto a los que tenían antes de migrar, pero principalmente en los rangos de ingreso medio y bajo; c) que las $\mathrm{M}$ lograron aumentar más sus ingresos que los hombres en el retorno. Quedará para un estudio posterior encontrar las causas de esto.

\subsection{Posición en el trabajo antes y después de migrar}

El cuarto componente del concepto integrador de reinserción laboral se refiere al cambio de posición en el trabajo, que implica la manera como se insertan en el mercado y la relación laboral que establecen. De todos es conocido que no es lo mismo ser empleado que empleador. Al retornar los que pasaron a ser dueños o socios de una empresa representaban casi $17 \%$, cuando antes de migrar eran casi 11\%. Igual los trabajadores por cuenta propia, los cuales más que duplicaron su participación al pasar de $15 \%$ a $35 \%$ en el retorno. Por su parte, los clasificados como empleados u obreros privados disminuyeron su participación de $64 \%$ a $36 \%$, en este rubro fue donde se presentó el ajuste, ya que la categoría de empleado público municipal también aumentó su participación de $9 \%$ a $12 \%$ (gráfica 7).

Lo anterior tiene varias implicaciones: a) una pequeña parte se convirtió en empleador gracias al uso de sus remesas y ahorros, y también a los elementos adquiridos en su experiencia migratoria; $b$ ) poco más de una sexta parte de la muestra pasaron a ser trabajadores por cuenta propia, es decir, a desempeñar una actividad independiente que en su mayoría

\section{Gráfica 7 \\ Posición en el trabajo antes y después de migrar}

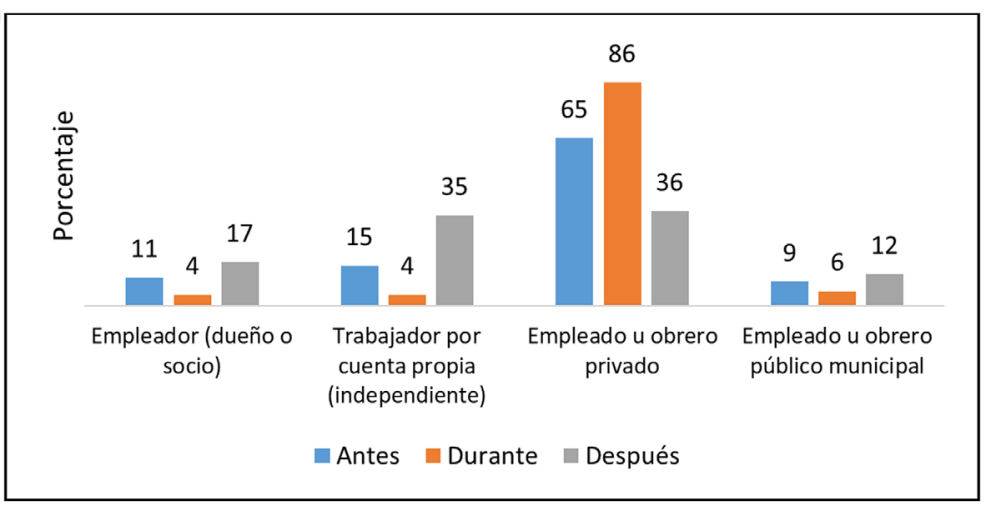

Fuente: elaborado con resultados de encuesta aplicada a migrantes de retorno en el municipio de Cuautlancingo, Puebla, 2015-2016 (Ibero/Puebla-BUAP, 2016). 
fue en el comercio informal, con bajos salarios y sin prestaciones; $c$ ) los que regresaron y continuaron siendo empleados $\mathrm{u}$ obreros se mantuvieron bajo una relación de dependencia laboral, con ingresos bajos-medios y prestaciones de ley como el seguro social que les daba cierta tranquilidad, es de mencionar que este reducido grupo fue el que pudo insertarse de mejor manera a las actividades modernas más relacionadas con la globalización, como el comercio formal de mayor escala y específicamente la industria manufacturera y de la construcción; y $d$ ) también aumentaron los empleados públicos, tanto de nivel medio como bajo, estos fueron retornados con una base económica que les permitió incursionar en la política y en puestos públicos a nivel de juntas auxiliares del gobierno municipal, donde muy probablemente su experiencia migratoria en términos de conocimientos, habilidades y actitudes les daba cierto prestigio y ventaja.

\section{Condiciones, obstáculos y expectativas}

Si bien las características personales son determinantes en los procesos de reinserción social y laboral, también las condiciones del entorno lo son (Mestries, 2013), porque serán las que permitirán sentar las bases para una permanencia estable por lo menos económicamente, y más todavía cuando son producto de la percepción y valoración de los retornados (Rivera-Sánchez, 2015). Así, las principales respuestas sobre las condiciones que facilitaban la reinserción fueron: para $64 \%$ de ellos, que existan empleos, siendo esto una de las causas de la migración que nuevamente les afecta en el retorno; para 17\%, que exista una oficina de atención a los migrantes que les informe sobre trámites administrativos y a donde recurrir para capacitarse. Para 12\% de ellos, que existan buenas condiciones de vida en la comunidad, como la seguridad.

En la misma tónica se expresaron sobre los obstáculos que han y están enfrentando. Para 39\% la falta de empleo, para 19\% el diferencial salarial entre México y EE.UU., y para otro 19\% deficiencias en el uso del español como idioma, el clima y algunas costumbres que contrastaban con las del país del norte, en este caso eran retornados con familia y con más duración en la experiencia migratoria. En menor medida pero no menos importante, mencionaron que por su condición de retornados han sentido rechazo social, esto también ha sido reportado por Rivera-Sánchez (2015).

En la complejidad del retorno las percepciones de los retornados ayudan a entender su realidad y sus aspiraciones. Como se ha dejado ver antes, la mayoría de los encuestados no había cumplido con sus metas antes de haber retornado, pues tenían planeado vivir hasta cinco años más 
en EE.UU. Por lo tanto deseaban al menos poder mandar a sus hijos a vivir y estudiar a aquel país, y ellos mismos poder regresar. Al margen de que lo pudieran hacer o no, sus expectativas revelaron que la reinserción social y, en especial, la económica laboral, en casi la mitad de las $\mathrm{M}$ y en la mayoría de los $\mathrm{H}$, no ha sido satisfactoria.

\section{Conclusiones}

Aprovechando que la edad promedio de los migrantes en retorno fue de 30 años (plena edad productiva) y su antigüedad promedio en la migración de cinco años (mediana duración de la experiencia migratoria), los resultados sobre sus características y procesos de reinserción económica presentan caras de una realidad en la periferia globalizada, como es el municipio de Cuautlancingo, que podrían estarse repitiendo en otros lugares de México.

Así, una vez analizado el proceso de reinserción laboral, como elemento central de la reintegración económica al retornar, se puede concluir que no ha sido fácil, que no ha sido igual para mujeres y hombres, que ha sido un tanto diferente para quienes regresaron de manera definitiva voluntaria, que para los que regresaron bajo condiciones forzadas o regresaron voluntariamente pero sin metas cumplidas; que el uso de las remesas y de los ahorros en el retorno ha sido fundamental para lograr una reinserción económica laboral menos escabrosa, tal es el caso de casi la mitad de los encuestados que habían logrado aumentar sus bienes patrimoniales. Sin embargo, no todos los retornados regresaron con ahorros y no todos tuvieron tiempo para usar las remesas principalmente con fines patrimoniales o productivos.

La mayoría de ellos se emplearon nuevamente en el sector terciario de la economía pero en actividades de baja productividad, coincidente con Conway y Cohen (1998), incluso una buena parte se ha autoempleado y participa en actividades informales.

Igualmente, menos de un tercio logró una movilidad ocupacional ascendente, más las $\mathrm{M}$ que los $\mathrm{H}$, no obstante los conocimientos, habilidades y actitudes adquiridos durante la experiencia migratoria; esto fue así porque las condiciones de los mercados laborales y de la economía local en su conjunto, no ofrecían oportunidades de mejores empleos, parecido a lo reportado por Padilla y Jardón, (2014).

Aunque una buena parte aumentaron sus ingresos al retorno con respecto a antes de migrar, sus ingresos seguían siendo muy bajos como en la media nacional, lo cual los limitaba para ahorrar y continuar con sus procesos de formación de patrimonio. 
Por último, muy pocos lograron mejorar su posición en el trabajo emprendiendo una empresa o negocio, y aunque poco más de la tercera parte realizaba trabajo de manera independiente, también es cierto que en su mayoría lo hacían de manera improvisada y como alternativa frente al desempleo, como lo reportaron Mezger-Kaveder y Flahaux (2013), de tal suerte que la flexibilidad laboral acompañaba más en la informalidad y en condiciones de precariedad. Aunque se presentó un aumento de las posiciones salariales, otro grupo regresó a las mismas condiciones laborales de empleado, pero los ingresos que percibían en su mayoría eran menores a los de antes de migrar, algo similar encontraron Gandini et al. (2015: 119).

Debido a que la mayoría regresaron sin haber cumplido sus metas, que en los hechos representaría no haber preparado su retorno, esto es, no haber enviado suficientes recursos económicos y movilizado redes, contactos y relaciones hacia el lugar de retorno, se observa un importante grado de vulnerabilidad frente a las estructuras y relaciones de los mercados laborales, que coincide con lo planteado por Gandini et al., (2015), pero más acentuado para las $\mathrm{M}$, como también lo afirman Albo et al. (2012).

Por otra parte, las respuestas dan testimonio de procesos de reinserción complejos para los retornados $\mathrm{H}$ y $\mathrm{M}$, denotan que las condiciones de esta economía local invadida por los flujos de la globalización son muy limitadas para ofrecer oportunidades de progreso a los oriundos de Cuautlancingo, sobre todo a los retornados, a pesar de los conocimientos, habilidades y actitudes adquiridos en su experiencia migratoria, por lo que se emplean en lo que encuentran y con bajos ingresos. Circunstancias desalentadoras que los llevan a estados de insatisfacción y frustración que no expresan directamente, sino a través de sus expectativas, casi la mitad de las $\mathrm{M}$ y de los $\mathrm{H}$ retornados estaban pensando regresar a los EE.UU., alternativa casi agotada al menos durante la actual presidencia en aquel país, por lo tanto para muchos el retorno es final y no temporal.

Otra conclusión es que la migración puede resolver problemas económicos de las personas a nivel individual o familiar, de forma relativa y temporal, pero sus alcances son muy limitados para mejorar las condiciones laborales en el retorno. Los problemas estructurales de funcionamiento de las economías y de los mercados laborales en las comunidades de origen, en las regiones y a nivel nacional, siguen siendo los determinantes para la reinserción económica de los migrantes retornados. Esto es, en el contexto local de una estructura económica de ensamble automotriz y maquiladora no se logran insertar los retornados, porque se trata de un mercado laboral segmentado y precarizado que choca con el perfil y la experiencia de los migrantes retornados. 
Por ello, se requiere de un plan de desarrollo incluyente para el país y en cada nivel de gobierno para aprovechar todo el potencial de los $\mathrm{H}$ y $\mathrm{M}$ retornados. Ahí están sus cualidades y talentos de muchos, aprendidos o vividos en su experiencia migratoria, que pueden ser los catalizadores de una renovación de la cultura nacional con más respeto a las instituciones, al trabajo productivo y honesto, a la igualdad de género, en contra de la corrupción y la impunidad, a favor de la tolerancia y del rescate de los valores cívicos que prácticamente se han perdido, y que tanta falta hacen para la cohesión y la solidaridad social frente al gigante avasallador del norte.

Es fundamental que regrese el desarrollo de la comunidad, que se restablezca el tejido social y la integración de los aparatos productivos locales, basados en los recursos regionales y en el consumo de lo producido en la comunidad preferentemente. La defensa y vivencia de la cultura local es clave para lograr una inserción económica, selectiva y estratégica en el ámbito nacional e internacional.

Complementario a lo anterior y porque se han quedado solos en el retorno, es urgente que las políticas de atención a retornados tengan una dimensión de género, un tratamiento especial a los deportados y a los retornados frustrados, un enfoque en la reinserción social (educación) y laboral, que reconozca, valide y certifique al retornado y sus competencias laborales, pero sobretodo que les ayude a abrir las puertas de los empleadores.

Como la migración de retorno es una problemática que afecta tanto a México como a EE.UU., por las implicaciones que tiene, es necesaria la construcción de políticas y de programas binacionales de atención, con un enfoque integral. Programas de retorno voluntario y planeado con seguimiento y coordinación por etapas con resultados tangibles (Schramm, 2011; Parella y Petroff, 2014), para que los retornados y sus familias logren procesos de reinserción más dignos, financiados por las oficinas del trabajo de los dos países y por agencias internacionales, pero gestionados por organizaciones no gubernamentales con reconocimiento internacional.

Con esto y más, las autoridades de los tres niveles de gobierno deben estar preparadas, para que junto con los diferentes grupos de la sociedad civil puedan recibir en los próximos meses y ańos, a la gran cantidad de personas que retornarán de los EE.UU. de manera voluntaria o forzada.

\section{Fuentes consultadas}

Accem (Asociación Comisión Católica Española de Migraciones) (2009), "Experiencias sobre el retorno", Accem/Proyecto RN Latam, 
Madrid, España, <https://www.accem.es/wp-content/ uploads/2017/07/LATAM_ESP1.pdf>, 12 de febrero de 2018.

Acobe (Asociación de Cooperación Bolivia España) (2010), "La experiencia del retorno...", Estudio del caso boliviano, ACOBE, Madrid, España, <http://acobe.org/doc/LaExperienciaRetorno.pdf>, 13 de febrero de 2018 .

Albo Marquez, Adolfo; Juan Luis Ordaz-Díaz y Juan José Li Ng (2012), "Inserción laboral y características de los migrantes mexicanos de retorno 2005-2011. Comparación urbana-rural", en Telésforo Ramírez García y Manuel Ángel Castillo (coords.), El estado de la migración. México ante los recientes desafíos de la migración internacional, Consejo Nacional de Población y Vivienda, Ciudad de México, México, pp. 237-267.

Batista, Catia; Tara McIndoe-Calder y Pedro Vicent (2014), "Return migration, self-selection and entrepreneurship in Mozambique", discussion paper núm. 8195, IZA Institute for the Study of Labor, Bonn, Germany, <http://citeseerx.ist.psu.edu/viewdoc/downloa d?doi=10.1.1.645.9890\&rep=rep1\&type=pdf $>, 22$ de febrero de 2018.

BBVA-Conapo (Banco Bilbao Vizcaya Argentaria-Consejo Nacional de Población) (2015), “Anuario de Migración y Remesas", Fundación BBVA Bancomer y Secretaría de Gobernación, Ciudad de México, México.

Canales, Alejandro (2012), "La Migración mexicana frente a la crisis económica actual. Crónica de un retorno moderado", Revista Interdisciplinar da Mobilidade Humana, 20 (39), Centro Scalabriniano de Estudios Migratorios, Brasilia, Brasil, pp. 117-134, <http://www.redalyc.org/articulo.oa?id=407042016007>, 6 de febrero de 2017.

Cassarino, Jean Pierre (2004), “Theorizing Return Migration: The Conceptual Approach to Return Migrants Revisited”, International Journal on Multicultural Societies, 6 (2), European University Institute-Robert Schuman Centre for Advances Studies-Mediterranean Programme Series, Florencia, Italia, pp. 253-279, $<$ https://hal.archives-ouvertes.fr/hal-01237439/document>, 27 febrero de 2017. 
Castillo, José (1997), "Teorias de la migración de retorno", OIM Organización Internacional para las Migraciones, Universidad Complutense, mimeo, Madrid, España. <http://ruc.udc.es/dspace/bitstream/2183/9664/1/CC_33_art_3.pdf>, 16 de enero de 2017.

Cerase, Francesco (1974), "Expectations and reality: a case study of return migration from the United States to Southern Italy", International Migration Review, 8(2), Center for Migration Studies of New York Inc, Nueva York, Estados Unidos de América, pp. 245-262.

Cobo, Salvador (2008), “Cómo entender la movilidad ocupacional de los migrantes de retorno? Una propuesta de marco explicativo en el caso mexicano", Estudios Demográficos y Urbanos, 23 (1), El Colegio de México, Ciudad de México, México, pp. 159-177.

Conway, Dennis y Jeffrey Cohen (1998), "Consequences of migration for mexican transnational communities", Economic Geography, 74 (1), Clark University, Massachusetts, Estados Unidos de América, pp. 26-44.

Corona-Jiménez, Miguel y Marcela de Ávila Guerra (2017), “La migración de retorno, el gran reto de la segunda década del siglo XXI. Un estudio regional en Puebla”, en Liliana Meza González, Carla Pederzini Villarreal y Magdalena Sofía de la Peña Padilla (coords.), Emigración, tránsito y retorno en México, ITESO, Universidad Jesuita de Guadalajara, Universidad Iberoamericana, Guadalajara, México, pp. 183-214.

Corona-Jiménez, Miguel (2014), "Las remesas y el bienestar de las familias migrantes”, Perfiles Latinoamericanos, 43 (1), Facultad Latinoamericana de Ciencias Sociales-México, Ciudad de México, México, pp. 185-207.

Corona-Jiménez, Miguel; Benjamín Ortíz y Michele Corona (2014), "La migración en las regiones del estado de Puebla, en el contexto de las carencias y de los factores externos 2000-2010”, en Adriana Ortega Ramírez, Cristina Carvajal Cruz y Misael González Ramírez (coords.), Puebla y sus migrantes, tendencias y retos de agenda pública, Gernika Ediciones, Ciudad de México, México, pp.11-36.

Corona-Jiménez, Miguel (2008), "La economía de migrantes poblanos en Nueva York”, Migraciones, núm. 24, Instituto Universitario de 
Estudios sobre Migración, Universidad Pontificia de Comillas, Madrid, España, pp. 57-84.

Corona-Vazquez, Rodolfo (2000), "Monto y uso de las remesas en México", en Rodolfo Tuirán, (coord.), Migración México-EEUU. Opciones de politica, Consejo Nacional de Población y Vivienda, Ciudad de México, México, pp. 168-190.

Durand, Jorge (2006), "Los inmigrantes también emigran: la migración de retorno como corolario del proceso", Revista Interdisciplinaria de Movilidad Humana, 14 (26 y 27), Brasilia, Brasil, pp. 167-189, <http://www.redalyc.org/pdf/4070/407042004009.pdf>, 23 de enero de 2017.

Durand, Jorge (2004), "Ensayo teórico sobre la migración de retorno. El principio del rendimiento decreciente", Cuadernos Geográficos, 35 (2), Universidad de Guadalajara, Jalisco, México, pp. 103-116, <http://www.ugr.es/ - cuadgeo/docs/articulos/035/035-006.pdf>, 23 de enero de 2017.

Durand, Jorge y Douglas Massey (2003), Clandestinos, Universidad Autónoma de Zacatecas-Miguel Ángel Porrúa, Ciudad de México, México.

EMN (European Migration Network) (2009), "Programas y estrategias referentes al retorno asistido y reintegración en terceros países", EMN, Madrid, España, < https://ec.europa.eu/home-affairs/sites/ homeaffairs/files/what-we-do/networks/european_migration_ network/reports/docs/emn-studies/assisted-return/25b._spain_ national_report_assisted_return_re-integration_study_final_ version_27january2011_es.pdf >, 13 de febrero de 2018.

Fernández-Guzmán, Eduardo (2011), "Revisión bibliográfica sobre la migración de retorno", Norteamérica, 6 (1), Centro de Investigaciones sobre América del Norte-Universidad Nacional Autónoma de México, Ciudad de México, México, pp. 35-68, <http://www. scielo.org.mx/pdf/namerica/v6n1/v6n1a3.pdf>, 15 de febrero de 2018.

Gandini, Luciana, Fernando Lozano Ascencio y Selene Gaspar Olvera (2015), "El retorno en el nuevo escenario de la migración entre 
México y EE.UU.", Consejo Nacional de Población, Ciudad de México, México.

Ibero/Puebla (Universidad Iberoamericana Puebla) y BUAP (Benemérita Universidad Autónoma de Puebla) (2016), "Encuesta aplicada a migrantes de retorno en el municipio de Cuautlancingo, Puebla, 2015-2016”, Ibero/Puebla-BUAP, Puebla, México.

Inafed (Instituto Nacional para el Federalismo y el Desarrollo Municipal) (2016), "Sistema Nacional de Información Municipal", Secretaría de Gobernación, Gobierno Federal, Ciudad de México, México, <http://www.snim.rami.gob.mx/>, 23 de enero de 2017.

Inegi (Instituto Nacional de Estadística y Geografía) (2014), Resultados Definitivos. Censos Económicos, Instituto Nacional de Estadística y Geografía, Aguascalientes, México.

Inegi (Instituto Nacional de Estadística y Geografía) (2010), XIII Censo de Población y Vivienda 2010, Instituto Nacional de Estadística y Geografía, Aguascalientes, México.

Klagge, Britta y Katrin Klein-Hitpab (2010), "High-skilled return migration and knowledge-based development in Poland", European Planning Studies, 18 (10), Taylor and Francis, Londres, Inglaterra, pp. 1631-1651, <https://www.researchgate.net/publication/233211377_High-skilled_Return_Migration_and_ Knowledge-based_Development_in_Poland>, 15 de febrero de 2018.

Li, Juan José (2015), "Migrantes mexicanos de retorno e informalidad", Situación Migración Mexico, primer semestre 2015, BBVA Research, Ciudad de México, México, pp. 39-54, <https://www. bbvaresearch.com/wp-content/uploads/2016/06/1507_ SitMigracionMexico_1S15.pdf>, 4 de noviembre de 2016.

Massey, Douglas y Kristin Espinosa (1997), "What's driving Mexico-U.S. migration? A theoretical, empirical, and policy analysis", American Journal of Sociology, 102 (4), Universidad de Chicago, Illinois, Estados Unidos de América, pp. 939-999.

McKinney, John (1962), “Tipología constructiva y teoría social”, Amorrortu, Buenos Aires, Argentina. 
Mestries, Francis (2013), "Los migrantes de retorno ante un futuro incierto”, Sociológica, 28 (78), Departamento de Sociología, Universidad Autónoma Metropolitana-Azcapotzalco, Ciudad de México, México, pp. 171-212, <http://www.redalyc.org/articulo. oa?id=305026407006>, 22 de enero de 2017.

Mezger-Kaveder, Cora Leonie y Marie Laurence Flahaux (2013), "Returning to Dakar: a mixed methods analysis of the role of migration experience for occupational status", World Development, núm. 45, Elsevier, Amsterdam, Holanda, pp. 223-238.

Montoya Arce, Jaciel; Renato Salas Alfaro y José Antonio Soberón Mora (2011), "La migración internacional de retorno en el Estado de México: oportunidades y retos", Gaceta laboral, 17 (2), Universidad del Zulia Maracaibo, Maracaibo, Venezuela, pp. 143-168.

Murphy, Rachel (2000), "Return migration, entrepreneurship and local state corporatism in rural China: the experience of two counties in south Jiangxi", Journal of Contemporary China, 9 (24), Taylor and Francis, Londres, Inglaterra, pp. 231-247.

OIM (Organización Internacional para las Migraciones) (2006), Fundamentos de Gestión de la Migración Vol. III, OIM, Ginebra, Suiza, <http://www.iom.int/.../EMM_SP_vol3_part1.pdf> 14 de febrero de 2018.

ONU (Organización de las Naciones Unidas) (2015), "International Migration Report", Department Economic and Social Affairs New York: Population Division, Nueva York, Estados Unidos de América, <http://www.un.org/en/development/desa/population/ migration/publications/migrationreport/docs/MigrationReport2015.pdf>, 23 de enero de 2017.

Padilla, Juan Manuel y Ana Elizabeth Jardón (2014), “Migración y Empleo: Reinserción de los migrantes de retorno al mercado laboral nacional", Proyecto Piloto, Fortalecimiento del diálogo y de la cooperación entre la Unión Europea y América Latina y el Caribe para el establecimiento de modelos de gestión sobre migración y políticas de desarrollo, Instituto de Estudios y Divul- 
gación sobre Migración, Ciudad de México, México, <http:// www.migracion-ue-alc.eu/documents/proyecto_piloto_mexico/ Informe_proyectopiloto_Mexico.pdf>, 27 de febrero de 2017.

Parella, Sònia y Alisa Petroff (2014), “Migración de retorno en España: salidas de inmigrantes y programas de retorno en un contexto de crisis", Anuario CIDOB de la Inmigración (edición 2014), Barcelona, España, pp. 63-87, <http://www.raco.cat/index.php/AnuarioCIDOBInmigracion/article/view/288374>, 16 de febrero de 2018.

Pascual de Sans, Ángels (1983), "Los movimientos migratorios de retorno, significación y perspectivas", Documents d'Anàlisi Geográfica, núm. 3, Universidad Autónoma de Barcelona, Barcelona, España, pp. 47-69. <https://core.ac.uk/download/pdf/13271237.pdf> 27 de febrero de 2017.

PEW (Pew Research Center) (2014), "U.S immigrant deportation declined in 2014, but remain near record high", PEW Research Center, Washington, Estados Unidos de América, < https://finchannel. com/index.php/world/59469-u-s-immigrant-deportationsdeclined-in-2014-but-remain-near-record-high>, 3 de marzo de 2017.

PEW (Pew Research Center) (2016), "5 facts about illegal immigration in the U.S.", Pew Research Center, Washington, Estados Unidos de América, <http://www.pewresearch.org/fact$\operatorname{tank} / 2016 / 09 / 20 / 5$-facts-about-illegal-immigration-in-the-u-s/>, 3 de marzo de 2017.

Reinhold, Steffen y Kevin Thom (2013), "Migration experience and earnings in the mexican labor market", Journal of Human Resources, 1 (48), The Board of Regents of the University of Wisconsin System, Wisconsin, Estados Unidos de América, pp. 768-820, $<$ http://jhr.uwpress.org/content/48/3/768.full.pdf+html>, $17 \mathrm{de}$ febrero de 2018.

Rivera-Sánchez, Liliana (2015), "Narrativas de retorno y movilidad. Entre prácticas de involucramiento y espacialidades múltiples en la ciudad", Estudios Políticos, núm. 47, Instituto de Estudios Políticos, Universidad de Antioquia, Medellín, Colombia, pp. 243-264. DOI: 10.17533/udea.espo.n47a14. 
Schramm, Christian (2011), "Retorno y reinserción de migrantes ecuatorianos: La importancia de las redes sociales transnacionales", CIDOB d'Afers Internacionals, núm. 93-94, ISLAM POLÍTICO EN EL MEDITERRÁNEO: Transformación y adaptación en un contexto cambiante, Jstor, Barcelona, España, pp. 241-260, <http://www.jstor.org/stable/25822787>, 19 de febrero de 2018.

SFA (Secretaría de Finanzas y Administración) (2016), "Información Básica del Municipio: Cuautlancingo, Sistema Estatal de Información", Gobierno del Estado de Puebla, Puebla, México.

Wang, Dan (2015), "Activating Cross-border Brokerage. Interorganizational Knowledge Transfer through Skilled Return Migration", Administrative Science Quarterly, 60 (1), SAGE journals, Nueva York, Estados Unidos de América, pp. 133-176, <http://journals. sagepub.com/doi/pdf/10.1177/0001839214551943>, 16 de febrero de 2018.

Zelekha, Yaron (2013), "The Effect of Immigration on Entrepreneurship", Kyklos, 66 (3), John Wiley and Sons, Nueva Jersey, Estados Unidos de América, pp. 438-465, DOI: 10.1111 / kykl.12031, 17 de febrero de 2018.

Recibido: 30 de octubre de 2017. Reenviado: 26 de enero de 2018. Aceptado: 8 de marzo de 2018.

Miguel Ángel Corona-Jiménez. Doctor en Administración de Organizaciones por la Universidad Nacional Autónoma de México. Actualmente es profesor-investigador del Departamento de Ciencias Sociales, Universidad Iberoamericana Puebla. Es miembro del Sistema Nacional de Investigadores, Nivel I. Sus líneas de investigación son: Migración de retorno bajo condiciones de cambio climático, Desarrollo Regional, Economía de los hogares, pensamiento y acción estratégica. Entre sus últimas publicaciones destacan: En co-autoría "Migrantes de retorno y movilidad laboral bajo condiciones de cambio climático en Puebla”, en Ana Ma. Aragonés (coord.), La reciente crisis financiera y el debate sobre migración y desarrollo. Propuestas para América Latina y México, Instituto de Investigaciones Económicas de la Universidad Nacional Autónoma de México, Ciudad de México, México, pp. 169-200 (2016); "Las remesas y el bienestar en las familias de migrantes", 
Perfiles Latinoamericanos, 43 (1), Facultad Latinoamericana de Ciencias Sociales-Sede México, Ciudad de México, México, pp. 185-207 (2014), y en co-autoría: "La migración en las regiones del Estado de Puebla, en el contexto de las carencias y de los factores externos 2000-2010", en Adriana Sletza Ortega Ramírez, Cristina Carvajal Cruz y Misael González Ramírez (coords.), Puebla y sus Migrantes. Tendencias y retos de agenda pública, Gernika ediciones, Ciudad de México, México, pp. 11-36 (2014). 